\title{
DESIGN PARAMETERS OF DRIVER SEAT IN AN AUTOMOBILE
}

\author{
Hanumant N. Kale ${ }^{1}$, C. L. Dhamejani ${ }^{2}$ \\ ${ }^{1}$ PG Student, Mechanical Engineering Department, JCEI's Jaihind College of Engineering, Pune, Maharashtra, \\ India. \\ ${ }^{2}$ Principal, JCEI’s Jaihind College of Engineering, Pune, Maharashtra, India
}

\begin{abstract}
Driver seat is an important system of any automobile, it is also complicated system consists of so many parts, adjustments as well as safety systems. A seat adjustment includes height adjustment, fore and aft adjustment, back recline adjustments. Safety systems include seat belts, air bags and advanced head restraints. Generally professional driver works more than eight hours per day of a week, therefore driver seat must be designed by considering all the parameters. Also uneven road condition induces the vibration in a vehicle transmitted to driver body. Poorly designed driver seat affects the driver health and psychological conditions of mind. Three main objectives of any driver seats are safety, health and comfort of driver. This paper presents all the parameters of driver seat such as anthropometry of human, ergonomics related parameters, seat materials, safety related parameters, comfort related parameters as well as weight and aesthetics with classifications and basics of driver seat.
\end{abstract}

Keywords: Driver Seat, Comfort, Safety, Health, Adjustments.

\section{INTRODUCTION TO DRIVER SEAT}

Driver seat is an inseparable part of any automobile. Its main function is not only to provide a seating space to driver but also support, protect and to provide comfortable seating posture to the occupants. Today driver seat design has been given very importance because poorly designed seat affect badly on human health as well as psychological condition of driver hence increases the chances of accidents. It is evolved after evolution of first car at the start of nineteenth century. Following table shows the evolution of driver seats with period and car where it is used.

Table-1: Evolution of Driver Car Seat [9]

\begin{tabular}{|l|l|l|}
\hline Introduced & Item & Example \\
\hline $1890-1900$ & Bench Seats & Philion \\
\hline $1900-1910$ & Deep Bucket Seats & Thomas \\
\hline $1910-1915$ & Fold-forward Backrests & $\begin{array}{l}\text { Model-T } \\
\text { Ford }\end{array}$ \\
\hline $1910-1915$ & Consol Between Seats & Wescott \\
\hline $1910-1915$ & Pedestral Seat & Agro Electric \\
\hline $1910-1920$ & Swivel Seat & Cole \\
\hline $1920-1925$ & Fold- down Armrest & Dusenberg \\
\hline $1925-1930$ & Fore- and -aft Adjustment & Viking \\
\hline $1950-1952$ & Power Seats & Packard \\
\hline $1960-1963$ & Optional Head Restraints & All U.S \\
\hline 1968 & Integrated Head restraints & Volkswagen \\
\hline 1969 & Standard Head Restraints & All U.S \\
\hline 1997 & Pro Active Head Restraint & Toyota \\
\hline
\end{tabular}

\subsection{Parts of Driver seat}

Driver seat is very complicated, consists of large number of parts and mechanisms. Main parts of driver seat are frame, padding, seat pan, head restraints system, reclining mechanism with lever, trim (seat cover), and suspension system, air bags, seat belt, fore and aft adjustment, height adjustment etc.

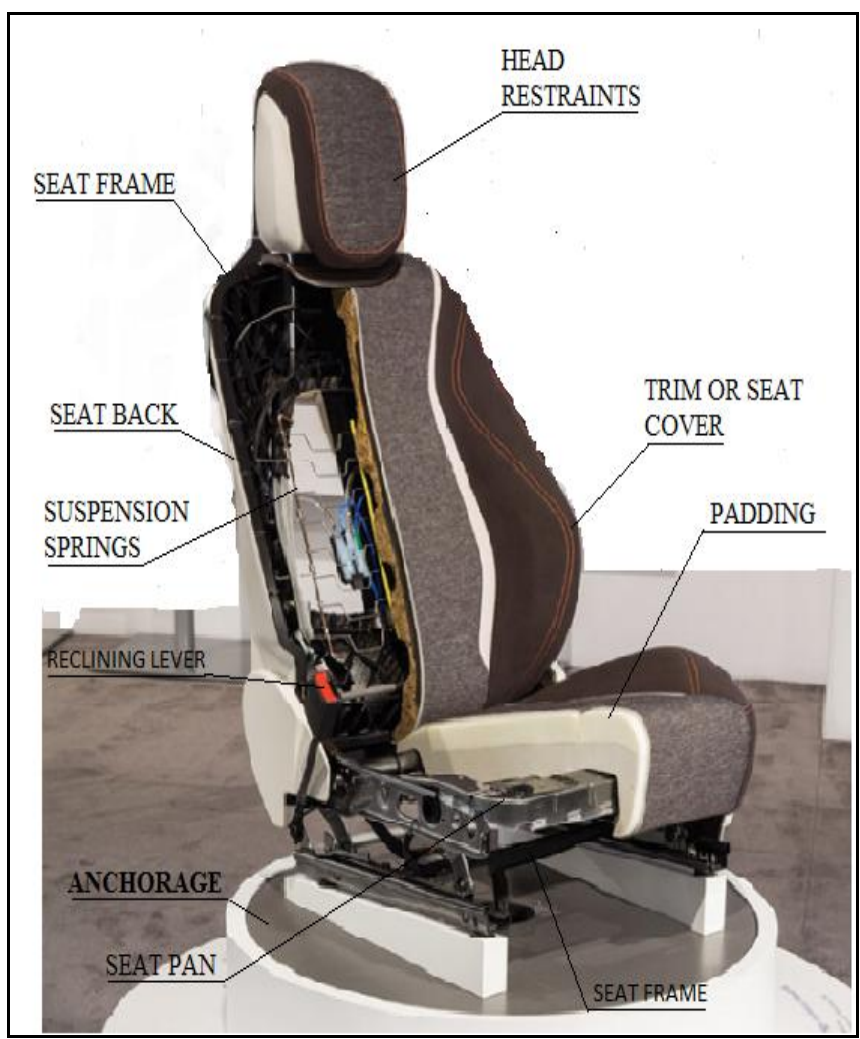

Fig-1: Cut section of driver seat components and systems

\subsection{Function of Major Components of Seat}

\subsubsection{Seat Frame}

It is most important part of any seat over which all other adjustment systems and components are mounted. It is made from HSLA (High Strength low alloy steel) tube [1] [2]. 


\subsubsection{Anchorage}

It is nothing but the space at which driver seat is mounted.

\subsubsection{Seat Cushion/ Padding}

It is that part of seat on which driver sit. It is soft and made from a resilient material such as PU foam of varying stiffness. Base and back cushions are used for seat [1] [2].

\subsubsection{Seat Back}

It is that part of seat which is vertical or somewhat inclined and supports the driver lumbar, shoulder and head. At the top of seat back generally a head restraint system is mounted. Angle of seat back can be adjusted with the help of back reclining mechanism.

\subsubsection{Seat Adjustments}

It includes height, fore and aft as well as back reclining adjustment systems used to adjust height, fore and aft distance and angle of back respectively.

\subsubsection{Head Restraint}

It is mounted over the seat back at top, its main function is to support head also restrict the backward displacement and protect the cervical vertebrae. There are four types of head restraints namely integrated, detachable, separate and proactive head restraints [1] [12]. Proactive is advanced version of head restraint.

\subsubsection{Suspension}

Generally at two places suspension is used namely seat base and seat back. For suspension springs are used. Main purpose of suspension system is to attenuate the vibrations from road at driver seat and his body.

\subsubsection{Trim}

It is nothing but outermost covering of a driver seat, made from a cloth or leather of good quality. It has pleasant colour, appearance as well as styling.

\section{PARAMETER AFFECTING DRIVER SEAT DESIGN}

Wide varieties of parameters must to be considered while designing a driver seat in order to fulfill the following four criteria's: 1. Driver seat is designed such a way that he can reach vehicle control with clear vision. 2 . Seat is designed in such a way that accommodates the driver size and shape.

3. For extended period of driving seat should provide comfort. 4. Seat must guard driver during accident or collision [2].

Following classification shows parameters affecting on the design of driver seat (see fig-2). There are main three types of parameters such as ergonomics related, overall weight of seat and aesthetic related parameters. These parameters again classified into sub parameters. We will discuss those parameters in details.

\subsection{Ergonomics Related}

Ergonomics is branch of design engineering applied to driver seat design requires that we take into consideration how the products we design fit the people that are using them. When seat fit to the driver it gives more comfort, less stress and maintains good psychological and health condition of driver. Ergonomics can be an integral part of design, manufacturing and use. Knowing how the study of anthropometry, posture, repetitive motion, and work space design affects the user is critical to a better understanding of ergonomics as they relate to end-user needs.

\subsubsection{Comfort Related Parameters}

Comfort is feelings like relief, encouragement, enjoyment and stable. Comfort is dependent on pressure distribution over the seat, thermal comfort, vibration at driver body, geometric parameters.

\subsubsection{Pressure Distribution Over Seat}

For better comfort and proper maintenance of driver health uniform pressure distribution along the human body over the seat is very important parameter. Pressure distribution over a seat is dependent on the properties of cushion material such as stiffness, deflection and design of cushion. Also it depends on nature of loading, seat pan design and backrest design. A proper seat pan contour distributes a uniform pressure over seat and avoids concentration of stress in human buttocks. Properly inclined back rest avoids stresses at buttocks.

\subsubsection{Thermal Comfort}

It is most important ergonomic parameter on which comfort as well as health of driver dependent. Generally seat cushion materials (seat cover, PU foam and coconut fibers) absorb heat from driver body any acts as heat reservoir, this phenomenon is good for health in winter season but responsible for un-comfort in summer season. This problem can be overcome by using different types of seat covers depending on seasons.

\subsubsection{Vibration}

Road surface is not uniform everywhere yet it is constructed properly by advanced technology. Such surface is responsible for vibrations at driver seats. Human body can sustain 4-7 Hz frequency vibrations. Some tractor semiactive hydraulic and active mechanical hydraulic actuators (i.e. suspension systems) are used to attenuate vibration transferred to the driver. Driver seat is so designed that very less vibrations transferred to driver.

\subsection{Geometric Parameters}

It includes the parameters like lumbar support, backrest slope angle, seat width, depth and height, seat pan angle. 


\subsubsection{Lumbar Support}

Driver works extended periods of times therefore proper lumbar support is very important in order to maintain the position of vertebrae. Large number of anthropometric data is required for proper design of seat which provides support to lumbar. Proper lumbar support can be achieved by maintaining profile of seat cushions of PU foam material.

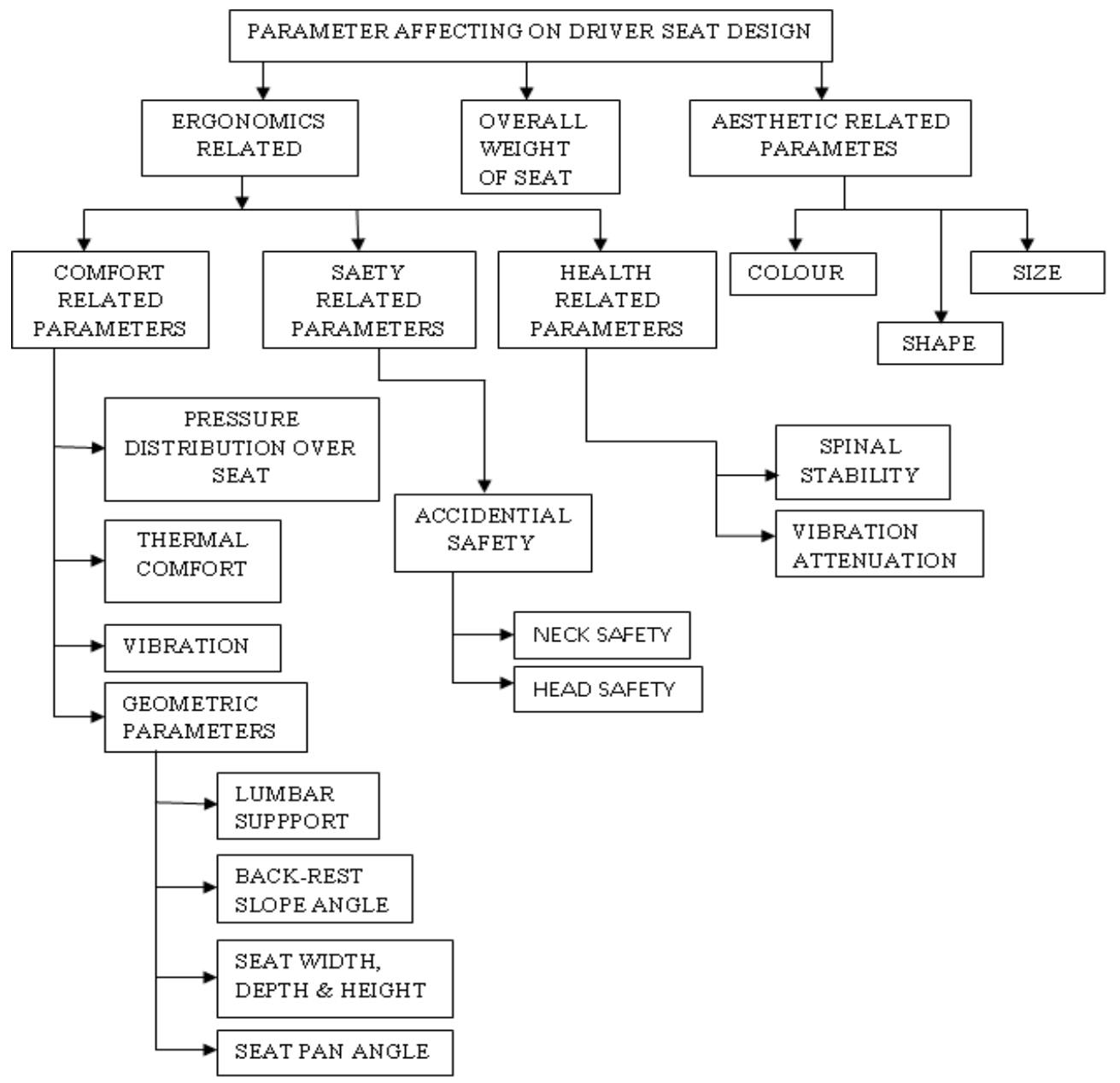

Fig-2: Classification of Parameters Affecting Design of Driver Seat

\subsubsection{Other Adjustments}

It includes other parameters apart from lumbar support.

Seat adjustments totally depend on driver body shape and size i.e. anthropometry. Therefore seat designer must study the huge amount of data related to anthropometry before building a first prototype. Seat angle is also responsible for pressure distribution over seat. Seat pan can be tilted in between $0-10^{\circ}$ angle depending on driver body shapes and sizes.

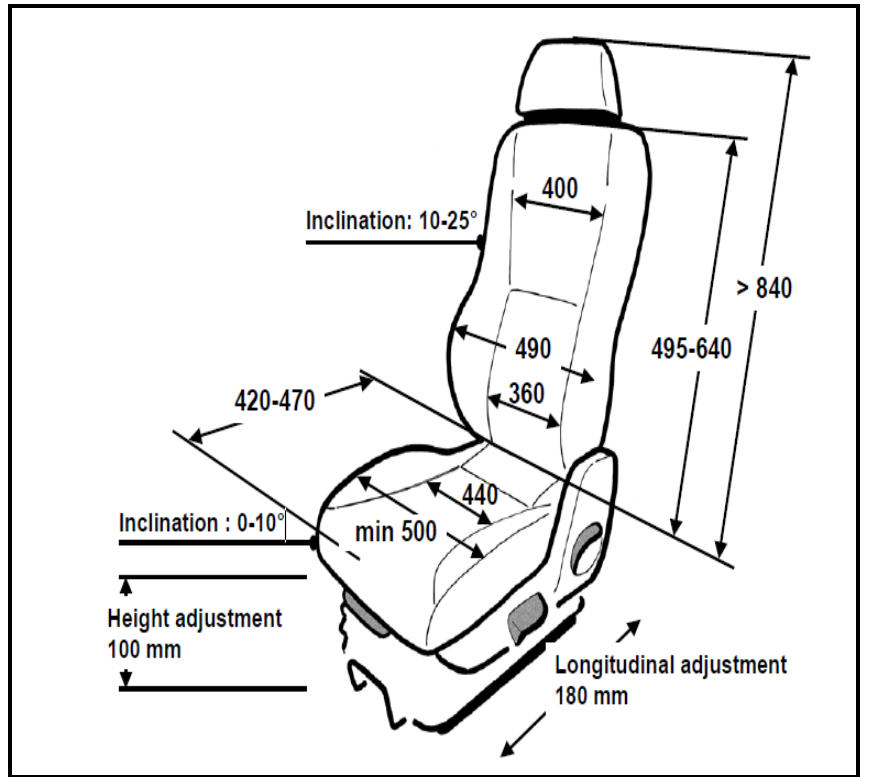

Fig -3: Various adjustments of motor coach driver seat 


\subsection{Safety Related Parameters}

Accidentals safety to the driver is most important thing while designing a driver seat. Safety to head, leg and entire human body is very important. For safety of head air bags are provided in seat and its compartments. Also active head restraint is best device for the safety of driver neck.

\subsubsection{Pro Active Head Restraint for Neck Safety}

Main function of any head restraint is to provide support to head during collision i.e. to minimize whiplash injury to neck. This is an advanced head restraint which uses a mechanism which activate during the rear end collision and catches driver head. By using such head restraint reduces the whiplash injury to neck by $10-20 \%$.

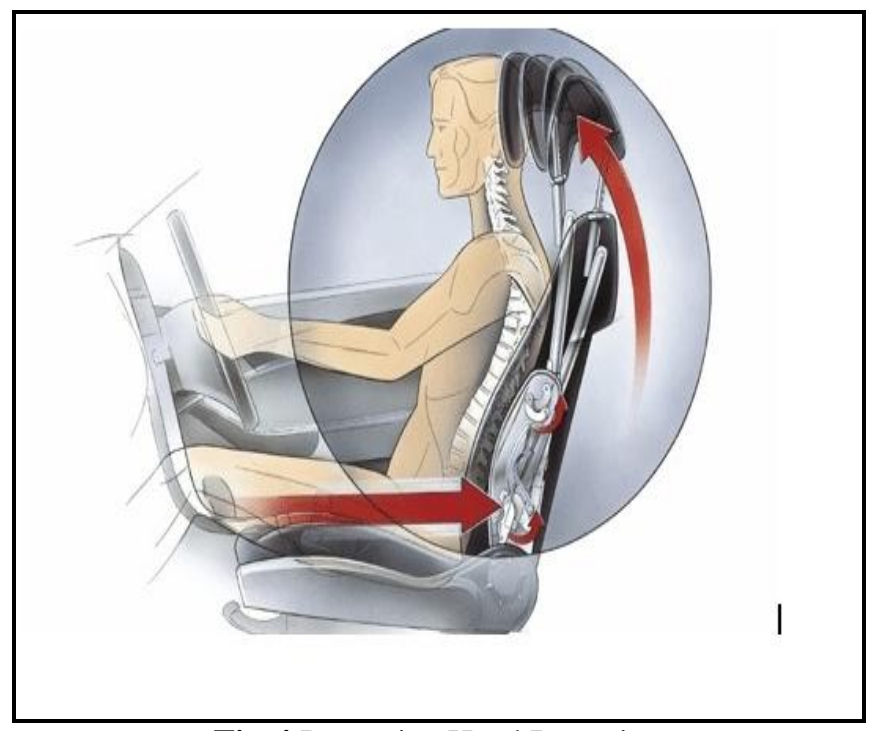

Fig-4 Pro active Head Restraint

\subsubsection{Head Safety through Air Bags}

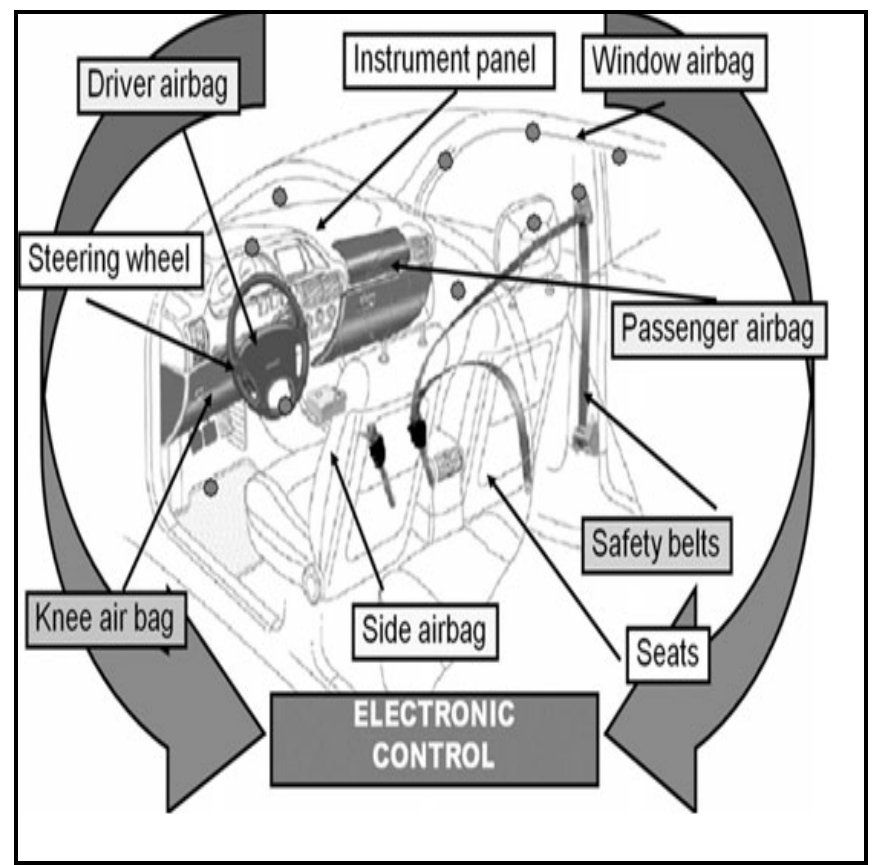

Fig-5 Position of air bags and seat belt for driver seat
Head is important part of human body, for its safety air bags are provided at front as well as at window side, which reduces the injuries to head during front and side collisions. Seat belt holds the driver body on the seat. To ensure the safety proper design of seat belt and position of air bags are very important part of design.

\subsection{Health of Driver}

Long driving period affects on human body so seat must be designed for high comfort and safety. Spinal stability is important while driving a vehicle. A well shaped seat cushion can support to the lumbar and maintain proper curvature of lumbar.

\subsection{Overall Weight of Seat}

Weight of vehicle affects on the fuel consumption of vehicle. In order to maintain low weight of a vehicle, driver seat must be light in weight. Designer must study the light weight materials and by using those materials a light weight seat can be designed. Life of seat is totally dependent on the quality of material used.

\subsection{Aesthetic Related Parameters}

Apart from strength, life, safety and materials used for seat, physical appearance of seat is most important factor to attract the customers and to increase the sale. Colour, shape and size of seat are three important aesthetic parameters of driver seat.

\subsubsection{Colour}

Trim is the outermost part of seat. So for better appearance its colour must be attractive and pleasant to the eyes. Also material of trim must be better quality and it does not absorb water as well as does not attract particles of dust, can be clean just by wiping out.

\subsubsection{Shape and Size}

Seat should be compact and well shaped so that it look better and suit to the driver body.

\subsection{Cost of Seat}

In order to fulfill the need of customer in minimum cost optimization and mass production of seat is very important aspect. But some time cost is not issue at that time designer can use high quality of material and all advanced safety systems in a driver seat (e.g. Military vehicles, seats of aero plane pilot etc).

\section{CONCLUSIONS}

Parameters affecting on driver seat design are very complex in nature and require detailed study of human anthropometry, seat dimensions, its mechanisms, materials of seat components and its functions, safety factors of driver, advanced systems for safety. Apart from all other parameters safety and health related parameters are very important. 


\section{ACKNOWLEDGEMENTS}

I take this opportunity to thank all those who have contributed in successful completion of this research paper. I would like to express my sincere thanks to my seminar guide Prof. H. R Mishra and project guide, Dr. C. L. Dhamejani, Principal JCEI's, Jaihind College of Engineering Kuran, who has encouraged me to work on this topic and offered valuable guidance wherever required. I am thankful to my parents to support me while studying over this topic.

\section{REFERENCES}

[1]. Automotive research association of India, "Automotive Industry Standards - Volume 4 (AIS 052: Code of Practice for Bus Body Design \& App)", PP 6-8.

[2]. Pachling Vishwanath K, Prof. Chaitanya S. V. (2013), "Revive of design aspects of major components of Automotive Seat", Asian Journal of Engineering and Technology Innovation 01(01)2013 33-38.

[3]. X. Shi, G. Paul, "Determinants of Driver vs. Second Row Occupant Posture Modelling".

[4]. Scott Openshaw, Erin Taylor, "Ergonomics and Design A Reference Guide" 2006 Allsteel Inc, pp 1-8.

[5]. Dr. Tim Springer "The Future of Ergonomic Office Seating" Knoll workplace research, Inc. 2010.

[6]. H.S.Dhingra, V.K.Tewari \& Santokh Singh, "Discomfort, Pressure Distribution and Safety in Operator's Seat - A Critical Review", Agricultural Engineering International: the CIGR Journal of Scientific Research and Development, Invited Overview Paper. Vol. V. July 2003.

[7]. CheeFai Tan, Wei Chen, Frank Delbressine and Matthias Rauterberg, "objectifying discomfort seat measurement for next generation truck driver's seat"

[8]. IS 13749 (2009): Automotive vehicles - Procedure for determining the ' $\mathrm{H}$ ' point and the torso angle for 50th percentile adult male in seating positions of motor vehicles.

[9]. Nurul Husna Binti Mohamad Shariff, "Anti Theft Design of Car Seat (Mechanical).

[10]. Jakob Steinwall, Atrik Viippola (2014 Sweden) "Concept Development of a Lightweight Driver's Seat Structure \& Adjustment System" pp-16-17.

[11]. T.C Fai, F. Delbressine and M. Rauterberg, "Vehicle seat design: state of the art and recent development" proceedings world engineering congress 2007, pp.51-61, Penang Malaysia.

[12]. http://www.gizmag.com/go/1615/

[13]. Lorenzo Morello, Lorenzo Rosti Rossini, Giuseppe Pia, Andrea Tonoli, "The Automotive Body", Volume-I: Component Design, ISSN 0941-5122, ISBN 978-94-0070512-8, e-ISBN 978-94-007-0513-5, DOI 10.1007/978-94007-0513-5 , Springer Dordrecht Heidelberg London New York, pp 560-602.

[14]. Dr. Sougata Karmarkar, Assistant Professor Department of Design, IIT Guwahati, "Design Course on Basic Ergonomics in Automotive design".

[15]. Information Document No. GRSG-91-3, “Driver's Workplace in Motor Coaches- Recommendations for Ergonomic Design", 91st GRSG, 17-20 October 2006, agenda item 1.2.9.
[16]. Mir Irfan Ul Haq, Ankush Anand, Tawqeer Nasir and Dhananjay Singh, "Design Considerations for Safety in Automobiles: A System Approach", at International Journal of Mechanical Engineering and Research, ISSN 2249-0019, Volume 3, Number 6 (2013), pp. 583-588

\section{BIOGRAPHIES}

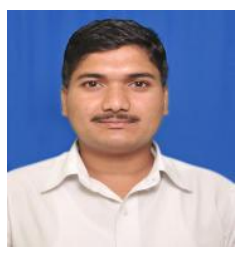

Mr. Hanumant N. Kale is researcher pursuing his Post Graduate (ME Design) from Jaihind College of Engineering, Kuran of Savitribai Phule University, Maharashtra, India. Also he worked as Assistant Professor.

hanumantkale10@gmail.com

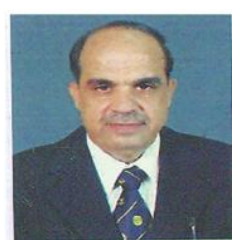

Dr. C.L. Dhamejani Principal JCEI's Jaihind College of Engineering, Kuran. He worked as Scientist in DRDO and director at VRDE Ahmednagar. Also completed doctorate from IIT Bombay in 1988.

chetan_dhamejani@rediffmail.com 